World Maritime University

The Maritime Commons: Digital Repository of the World Maritime University

\title{
Prosodic interference in maritime communication: nature and means of elimination
}

\author{
Bozhena B. Dokuto \\ Pyatigorsk State University (Novorossyisk Branch) \\ Igor O. Smirnov \\ Admiral Ushakov Maritime State University
}

Follow this and additional works at: https://commons.wmu.se/imla2021

Part of the Education Commons

\section{Recommended Citation}

Dokuto, B. B.\& Smirnov, I. O. (2021). Prosodic interference in maritime communication: nature and means of elimination. In Pazaver, A., Manuel, M. E., Bolmsten, J., Kitada, M., Bartuseviciene, I. (Eds.), Proceedings of the International Maritime Lecturers' Association. Seas of transition: setting a course for the future (pp. 162-169). World Maritime University. http://dx.doi.org/10.21677/imla2021.17

This Paper is brought to you courtesy of Maritime Commons. Open Access items may be downloaded for noncommercial, fair use academic purposes. No items may be hosted on another server or web site without express written permission from the World Maritime University. For more information, please contact library@wmu.se. 


\title{
Prosodic interference in maritime communication: nature and means of elimination
}

\author{
Bozhena B. Dokuto,
}

Professor, Novorossyisk Branch of Pyatigorsk State University, Russia, bojena20009@rambler.ru

\section{Igor O. Smirnov}

Professor, Admiral Ushakov Maritime State University (Russia), Zeherd@yandex.ru

\begin{abstract}
The paper is devoted to the analysis of typical phonological mistakes made by Russian-speaking maritime cadets and the teaching tools enabling maritime English instructors to correct them and to improve the phonological competence of maritime students. Today, addressing the issues of foreign accent in the speech of maritime professionals, one cannot underestimate the importance of the correct implementation of the prosodic system of the language being studied, since the quality of the implementation of a coherent text is undoubtedly the result of the adequate use in speech of both segmented and suprasegmental language means, that is separate phonemes and intonation. The comparison of the requirements of the Model Course 3.17 in phonology with cadets' test results assessment have displayed the phonological specificity of their accent which is allegedly caused by cross-cultural interference. The results of the study allow concluding that cognitive factors along with the prosodic system of the mother tongue belong to the interfering elements that cause phonological accent in speech in situations of professional communication, The main outcome of the research is determined by the opportunity to use the structured list of most typical prosodic errors in the process of forming cadets' Maritime English competence.
\end{abstract}

Keywords: prosodic competence, prosodic accent, prosodic interference, cognitions

\section{Introduction}

Nobody denies that maritime English being a global professional language possesses its specificity on the lexical and grammatical levels. However, we should admit the phonological level is also worth being taken into consideration in this respect. Displaying itself on the two sublevels: on the level of segmental phonemes and prosody, the Maritime English is affected by the interference of the mother tongue phonological system, which can create significant barriers in the process of professional and informal communication among seafarers. Such problems should be solved in order to prevent hazardous situations at sea and to maintain safety on board.

Thus, the relevance of the topic is conditioned by the necessity to further study issues of prosodic interference in the course of maritime professional communication taking into consideration the latest trends not only in the area of linguistics, but also in a number of adjoining areas.

The problem statement involves an assumption that prosodic interference in maritime English is revealed in the subsystems of the pitch, loudness and tempo. Consequently, a list of most 
typical prosodic errors made by Russian cadets speaking English can be used as a resource for elaborating tools of removing foreign prosodic accents.

The object of this study is the phenomenon of prosodic interference in maritime English caused by the influence of the mother Russian language.

The study is aimed at researching the nature of prosodic interference and analyzing tools of getting rid of prosodic accent in situations of professional communication at sea. The aim of the study determines the necessity to solve the following tasks:

- To characterize the concept of prosodic system and interference as well as the concept of phonological competence;

- To identify prosodic features most susceptible to foreign accent;

- To compare the influence of prosodic interference in cadets' reading aloud and quazi spontaneous speaking;

- To work out a series of tools aimed at correcting prosodic interference with cadets speaking Russian as a mother tongue.

The study involved methods of auditory, perceptive and comparative analysis with the further statistical treatment of the obtained results.

\section{The Concept of Prosodic Interference}

The formation of a foreign language system on the basis of the already formed system of the native language is a very complex process that directly affects human consciousness. In this process, factors such as the level of the professional's language proficiency, the usage area and degree of the two languages play a significant role. Prosodic interference is the least studied type of language interference. However, it is difficult to overestimate the role of prosody in the process of communication in general and professional communication in particular. It is necessary to note here that the term "prosody", "prosodic system" are interpreted here in a broad sense, as a term integrating elements of connected speech manifesting themselves in the form of sound simplification, rhythm and intonation (Wharton, 2012). It is widely known that prosody performs certain functions in creating the informative structure of the text in any language. Firstly, prosody is a means of expressing an attitude to a listener, to the situation and to the content of the utterance. Secondly, prosody performs a grammatical function in two aspects. It can distinguish a sentence type, and signal syntactic boundaries. This ability of prosody enables interlocutors to perceive speech in appropriate units. Thirdly, prosody is a tool to organize discourse. It reflects the information structure of the discourse and the logical connections between utterances (Underhill, 2005).

Psycholinguists claim prosodic interference is most stable in comparison with the native language influence on the vocabulary and grammatical layers of the foreign language. It is explained by the fact that prosody is formed even in the pre-speech period of the child (Bunina, 2004). However, the reasons for the appearance of a prosodic accent in a foreign language cannot be attributed only to the articulatory and prosodic differences of the contacted languages. Many scholars admit that prosody carries nationally specific cultural information that is directly related to the mentality of a certain ethnic group (Fomichenko, 2013).

This study understands the term "interference" as deviations from the language norm under the influence of the cognitions of the native language that arise as a result of the interaction of language systems in the conditions of bilingualism (Fomichenko, 2013). Cognitions are treated in this work as a set of mental processes that affect the perception of the world. They are 
present in human consciousness in the form of mentality, encyclopedic knowledge, linguistic knowledge and language abilities (Bunina, 2004; Fomichenko, 2013). Having realized the role of cognitions in causing prosodic interference makes it possible to model ways to eliminate them. The interfering influence of cognitions causes difficulties that arise in adults when learning a foreign language. Unlike a child, an adult has knowledge of the world in the form his native language presents it to him. Therefore, when learning a new language, one should see the world through the prism of another culture, another mentality.

The study of speech at the level of texts allows looking at this problem from the inside and constructing a prosodic model of the interfered system. The interfering influence of the prosodic system of the native language, along with cognitive factors, serves as an obstacle for maritime English students in the absolute mastery of maritime English.On the other hand, the influence of the national mentality on the prosodic organization of speech is one of the most significant reasons for the emergence of a prosodic accent in a foreign language. The role of cognitive factors of the native language in generating a prosodic accent should not be underestimated. The interfering influence of cognitions in the form of mentality, encyclopedic and linguistic knowledge, as well as language abilities predetermines the difficulties that naturally arise in the process of speech production in a foreign language, which is an integral part of professional communication at sea (IMO, 2000).

\section{The Perceptive Analysis of prosodic interference in quasi-spontaneous speech}

The influence of the mother tongue prosodic system on the prosodic features of a foreign English seafarer speaker has been analyzed perceptively in three main prosodic areas that characterize distinctive features of connected speech: sounds modifications to dictionary pronunciation, rhythmic organization of connected speech and intonation or speech melody. It is common knowledge that connected fluent native English speech is characterized by such features as vowel reduction of various degrees, elision or sound omission, contractions, liaison, juncture and assimilation (Underhill, 2005). These modifications are regular and predictable in English connected speech as it comprises a system. However, for Russian speaking learners they present a significant difficulty in both listening and speaking. Most first and second-year cadets do not reproduce such simplifications in their English speech. They tend to articulate all sounds fully as if they were reading separate words, which is caused by the influence of the Russian prosodic features of connected speech. Such ignorance of connected speech simplifications can make a speaker not only sound foreign, but also, cause phonemic mistakes that, in their turn, can lead to interruption and misunderstanding in situations of professional communication. For example, in the experimental test several Russian-speaking cadets pronounced one of the IMO phrases "Standby for mooring!" ignoring the phenomenon of juncture. They made a syllable boundary between "stand" and "by" in the verb "standby" which misleads the listener to the meaning "stand by..." (stand near). In this case, the phrase can be perceived as meaningless, like "Stand near for mooring!" which sounds incomplete as if missing an object.

It is interesting to stress that prosodic interference of the Russian language in the area of sound modifications in connected speech has a negative impact mostly on the adequacy of perceiving by ear. The well-known rule of devoicing voiced consonants word-finally in the Russian speaking is applied by inexperienced Russian-speaking cadets to the English discourse that can lead to serious distortions of meaning in professional communication. For example, the sentence "There's been an explosion in hold number four!" can be understood as meaningless due to the devoicing of [d] in "hold" and the absence of differentiation between [ou] and [o:] 
in the same word, as a result of which an interlocutor can hear "halt" (stop) instead of "hold". The experiment has also shown that not knowing the rule of elision, Russian-speaking undergraduates can mistake "Stand there!" for "Stan there!" (Stan as a male name) due to the prosodic interference which affects in this situation the process of listening.

The second essential element of the English prosodic system which is interfered by the Russian prosodic system in Russian seafarers professional communication is rhythm understood in this work and for teaching purposes as stress timing (Underhill, 2005). Stress timing as a tendency for stressed syllables together with preceding or following unstressed ones to occur at approximately equal intervals of time does not exist in the Russian prosody. Therefore, it requires special effort from Russian learners to master this feature. On the surface, it does not seem obvious that this typical element of the English prosody performs a relevant communicative function like sound modifications in fluent connected speech. Although it, certainly, creates a foreign prosodic accent, its absence does not lead to mistakes in communication. However, the experiment has shown that the prosodic interference of the Russian prosody reveals in this area either as the absence of distinction between notional (content) words and functional (grammar) words or as the wrong placing of the boundary between stress groups. The former error leads to eliminating distinction between neutral and emphatic structures, for instance, in the fragment of dialogue below "has failed" pronounced by the Russian speaker in two stress groups "'has |'failed" with the stressed "has", is understood as the speaker's insistence on the pump failure, which is not implied in the situation.

- Have you spoken to the engine room yet?

- Yes, Sir

- It seems the starboard pump has $\mid$ failed. The jacket water temperature is very high.

The wrong disposition of the boundary between stress groups due to the influence of the prosodic interference illustrated below can even cause a communication failure.

"I started the stand-|by pump manually."

The preposition "by" joining the following noun "pump" signals that this word combination performs the function of adverbial modifier of manner, i.e. it denotes a way of starting the stand. The sentence pronounced like this means that the speaker started some stand with the help of a pump, while in the real situation it should be timed as follows "I started $\mid$ the stand-by pump $\mid$ manually.", which means that "stand-by" is a type of a pump.

The third prosodic element which undergoes the impact of prosodic interference in our experiment is intonation or speech melody that is regarded in this work as pitch patterns of the voice which serves to distinguish syntactic structures, attitudes, informative structure of the discourse and links between utterances.

It is necessary to take into consideration essential differences in Russian and English pitch patterns. According to some Russian scholars (Bunina, 2004; Fomichenko, 2013), national specificity of modal and emotional relations manifests itself in the prosodic organization of speech in different languages. The British, considered to be traditionally reserved, are distinguished by a diverse range of pitch varieties in speech. Russians are traditionally characterized as tending to express emotions freely. This feature of their national mentality according to Fomichenko (2013) is expressed in the predominance of dynamic and temporal prosodic parameters in speech over tonal ones. The tonal modifications, presumably, play a secondary role in the prosodic system of the Russian language. 
The perceptive analysis has revealed that first-year Russian speaking cadets do not always distinguish communicatively significant information typical of English speech, focusing on other information centers. Incorrect distribution of energy on the key semantic segments of the phrase and insufficient knowledge of the English prosodic system lead to pitch inconsistencies between the use of the tone and the location of the semantic center in the phrase.

The conducted experiment and the analysis of its results enables us to construct a model of the Russian language intonation interference in the English speech in situations of professional communication at sea. This model includes tonal, temporal and dynamic characteristics (table 1).

Table 1

Model of Russian intonation interference

\begin{tabular}{|c|c|c|}
\hline Tonal interfered elements & Temporal interfered elements & Dynamic interfered elements \\
\hline $\begin{array}{l}\text { general monotony of } \\
\text { speech melody } \\
\text { the uniformity of tonal } \\
\text { characteristics on pre-nuclear } \\
\text { and nuclear parts of semantic } \\
\text { centers; } \\
\text { the use of low fall or } \\
\text { low rise in the nuclear } \\
\text { segment; } \\
\text { rise on the nuclear } \\
\text { syllable of the non-final nuclei } \\
\text { in the middle register of the } \\
\text { narrow range; } \\
\text { narrowed tonal range } \\
\text { of the terminal zone; } \\
\text { incomplete fall of the } \\
\text { narrow or middle range in the } \\
\text { nuclear segment in final } \\
\text { semantic centers; } \\
\text { reduction of nuclear } \\
\text { components of semantic } \\
\text { centers; } \\
\text { tonal variations on } \\
\text { functional parts of speech }\end{array}$ & $\begin{array}{l}\text { increased duration of } \\
\text { stressed short vowels; } \\
\text { slower speech tempo } \\
\text { due to ignoring reduction of } \\
\text { functional words and } \\
\text { hesitation pauses; } \\
\text { dislocation } \\
\text { numerous hesitation pauses } \\
\text { that disrupt stress timing }\end{array}$ & $\begin{array}{l}\text { dynamic highlighting } \\
\text { of pre-nuclear components of } \\
\text { semantic centers; } \\
\text { dynamic highlighting } \\
\text { of functional words in the } \\
\text { initial position of the } \\
\text { intonation group; } \\
\text { absence of secondary } \\
\text { stress in polysyllabic English } \\
\text { words. absence of bright } \\
\text { dynamic contrasts }\end{array}$ \\
\hline
\end{tabular}

It is essential to note that pitch pattern interference turned out to be the most significant in the prosodic space of maritime English since it always results in communication errors such as the violation of the topic-comment structure of the sentence and discourse, deviations from the intended attitude or communicative type of the syntactic structure. For example, the straightforward statements "We have checked all the /tanks. There's a rupture in /cargo tank." pronounced monotonously with a level, sometimes rising tone of a very narrow range as a result of the Russian language prosodic accent can be perceived by the interlocutor as questions. In addition, due to the Russian prosodic interference, Russian learners of maritime English at the beginning of the course cannot differentiate between proclaiming tones (Fall and Rise-Fall) and referring tones (Rise and Fall-Rise). They subconsciously build English speech into the Russian prosodic system levelling English pitch configuration and narrowing English pitch 
range. This effect is also achieved thanks to reducing the contrast in length and loudness between stressed and unstressed syllables.

\section{Tools of eliminating prosodic interference}

The results of the experiment conducted among first-year students revealed the problem areas and enabled working out a system of exercises capable of eliminating the consequences of prosodic interference of the native language determined by a number of cognitions. This system can be used as a means of improving cadets' communication skills both as listeners and speakers, and bring them closer to the quality of "comfortable intelligibility" [5]. The concept of "comfortable intelligibility" implies an ability to understand and to be understood when speaking in a foreign language on professional matters without undue effort, which corresponds to careful colloquial speech.

The teaching mechanism aimed at eliminating prosodic interference described in this paper consists of two phases; the receptive and productive ones. The work should be started with the listening phase. This receptive type of activity enables cadets to recognize prosodic features by ear. In this way, they gain knowledge of the English prosodic system and improved awareness of how prosodic features are related to British speaking culture and mentality. A maritime English learner listening menu at the first stage contains a wide selection of authentic texts of the total length of 120 minutes pronounced by native English speakers selected from free learning English resources such as BBC learning English site in the form of both monologue and dialogue. At the second stage, learners are offered to listen to authentic samples of professional maritime communication of the same length selected from Videotel and Marlins training resources.

At both stages, cadets are asked to write the transcript of the text in alphabetic spelling before listening and read the transcribed version. After that, they listen to the recording and compare their transcripts with what they actually hear, guided to identify cases of sound modifications. This inductive approach enables learners guided by teachers to make up a list of typical connected speech sounds modifications. Adult learners cannot skip this phase of analyzing and synthesizing distinctive features of fluent connected speech as they have a formed model of the native language prosodic system in their language consciousness. The next step of the receptive phase includes developing learners' rhythm (stress timing) awareness. At first, they listen to a sample of an authentic text and are offered to read it aloud straight after it is finished. They are offered to identify the difference in the number of prominences in order to attract their attention to their regularity. The next step involves a teacher's reproducing the same text fragment exaggerating the stress timing a little. Then students try shadowing the instructor's stress-timed speech lagging behind by one notional word at most, which is followed by the task to merge their speech with the instructor's, attempting to imitate the rhythmical patterns of the text. A curious approach also involves students' attempt to retell the text in Russian but within the framework of English stress timing. It works successfully since this prosodic discrepancy is revealed most brightly in this case. Finally, cadets record their reading and analyze their progress.

The same procedure is used for working out students' intonation competence. The observation step is followed by the analysis step when cadets mark relevant pitch movement in nuclear centres within intonation groups. The shadowing step is followed by parallel speaking and an attempt to impose English tonal contour on the Russian text of the same content. Then comes a rehearsing step when students try to reproduce all prosodic features of connected speech in 
juxtaposition. The final step includes recording students' attempts to imitate English speech and reflecting on their progress.

The third stage in the teaching mechanism presupposes a productive activity or modelling and acting out situations of professional communication at sea where learners can use maritime English rather than quoting it, being aware of the English prosodic system laws. It is important that this activity should be a holistic experience combining all prosodic features of fluent connected speech such as sound modifications, stress timing and speech melody. It should be based on learners' awareness of the prosodic requirements instead of an imitation mechanism since only such an approach can result in eliminating prosodic interference. Cadets are offered concrete situations within the range of such navigators' professional activities as entering or leaving a port, communication on the bridge, areas of navigational risks such as passing through narrows, shallow waters, mooring, towing, bunkering, berthing operations, etc. They first think over the ways of achieving their communicative goals by means of vocabulary and grammar resources, and then they rehearse speaking in groups several times. By the end of the rehearsing phase, they start concentrating not only on what is said, but also, on how it is said. Finally, they dramatize the situations to the whole group while listeners are to note down any signs of the Russian prosodic interference. In this way, cadets obtain an opportunity to give feedback on the presence of prosodically interfered features or their absence, which also reveals their improved prosodic awareness.

The practical application of the prosodic interference elimination mechanism described above has proved its efficiency in the classroom and self-training process at Admiral Ushakov Maritime State University.

\section{Conclusion}

By way of conclusion, it is necessary to stress that the nature of prosodic interference is determined by such cognitions as national mentality, encyclopedic knowledge and linguistic knowledge. This fact indicates that prosody can be approached through cognitive intervention, though only partly, as, according to many scholars, prosodic elements are controlled by a different part of the brain, which linguistically means subconsciously to some extent (Underhill, 2005; Wharton, 2012).

Learners' unawareness of cultural and prosodic differences lead to their inability to hear the discrepancies and to reproduce them in their speech when communicating also professionally. It is displayed in violations the prosodic norms of the English speech such as the rules of combining words in connected speech, functioning of rhythmic units in the form of stress timing, intonation groups and phrases in the text, the lack of necessary pauses between phrases, the inability to divide a phrase into semantically relevant chunks.

If the prosodic skill of the foreign language being studied is not purposely developed in learners, the prosodic design is built fully subconsciously, relying on the already formed prosodic model of the native language. That is why functional (grammar) words, which are usually not emphasized in English by stress and are not marked by pitch variations, are the most vulnerable interfered segments in maritime English spoken by Russian learners. The perceptive analysis demonstrates prosodic contrasts between semantic centers and pre-nuclear as well as postnuclear parts of the intonation groups are not distinct, which prevents the adequate information exchange in the process of professional communication. 
The prosodic interference elimination mechanism used in training navigators at Admiral Ushakov Maritime State University includes three phases. The two initial stages are of the receptive nature. They are aimed at providing cadets with awareness of the prosodic specificity of the English speech conditioned by the specificity of the British mentality and culture of speech. The third most important productive stage encourages cadets to apply their knowledge of the prosodic system by practicing quasi-real situations of professional communication. There is a transition step between the receptive and productive stages that implies modelling and rehearsing professionally-oriented dialogues.

We hope the results of this study can be of interest to researchers into methods of teaching as well as those who deal with issues of intonology. However, they are of more topicality to practicing maritime English instructors.

\section{References}

Bunina E. (2004) Specifics of prosodic interference in the situation of artificial trilingualism: Author's summary of the candidate of philological science dissertation. Volgograd: Volgograd University Press.

Fomichenko L. (2013) Linguo-semiotic peculiarities of the bilinguals' prosodic speech organization. Science Journal of VolSU, 12(1), 79-83

IMO. (2006). International Convention on Standards of Training, Certification and Watchkeeping for Seafarers, 1978

IMO.(2000) Model Course 3.17: Maritime English. International maritime Organization

Underhill A. (2005). Macmillan Books for Teachers. Sound Foundations. Learning and teaching pronunciation. Macmillan Publishers Ltd.

Wharton T. (2012). Prosody and meaning: theory and practice. In: J. Romero-Trillo (Ed.) Pragmatics, Prosody and English Language Teaching (pp. 97-116). Dordrecht, Netherlands : Springer. 